\title{
2014 JPBM Communications Award
}

The 2014 Communications Award of the Joint Policy Board for Mathematics (JPBM) was presented at the Joint Mathematics Meetings in Baltimore, Maryland, in January 2014.

The JPBM Communications Award is presented annually to reward and encourage journalists and other communicators who, on a sustained basis, bring mathematical ideas and information to nonmathematical audiences. JPBM represents the American Mathematical Society, the American Statistical Association, the Mathematical Association of America, and the Society for Industrial and Applied Mathematics. The award carries a cash prize of US $\$ 1,000$.

Previous recipients of the JPBM Communications Award are: James Gleick (1988), Hugh Whitemore (1990), Ivars Peterson (1991), Joel Schneider (1993), Martin Gardner (1994), Gina Kolata (1996), Philip J. Davis (1997), Constance Reid (1998), Ian Stewart (1999), John Lynch and Simon Singh (special award, 1999), Sylvia Nasar (2000), Keith J. Devlin (2001), Claire and Helaman Ferguson (2002), Robert Osserman (2003), Barry Cipra (2005), Roger Penrose (2006), Steven H. Strogatz (2007), Carl Bialik (2008), George Csicsery (2009), Marcus du Sautoy (2010), Nicolas Falacci and Cheryl Heuton (2011), Dana Mackenzie (2012), and John Allen Paulos (2013).

\section{Citation}

The 2014 JPBM Communications Award was presented to DANICA MCKELLAR, an actress (The Wonder Years, The West Wing), a published mathematician (while earning her bachelor's degree in mathematics at the University of California Los Angeles), an advocate for mathematics education, and a New York Times best-selling author. Her books, blog, and public appearances have encouraged countless middle and high school students, especially girls, to be more interested in mathematics.

Her books include Math Doesn't Suck: How to Survive Middle-School Math Without Losing Your Mind or Breaking a Nail (2007), Kiss My Math: Showing PreAlgebra Who's Boss

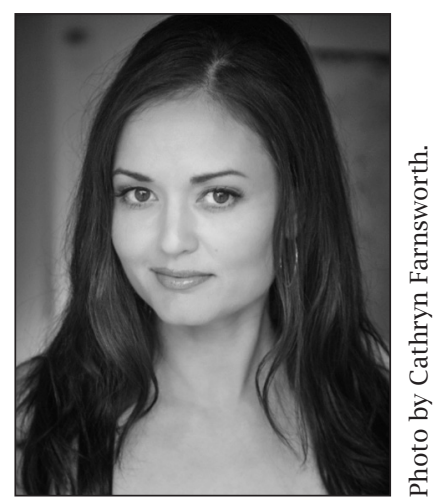

Danica McKellar (2008), Hot x: Algebra Exposed (2010), and Girls Get Curves: Geometry Takes Shape (2012). Their brilliant presentation of mathematical concepts in ways that relate to young girls have attracted a huge audience that includes both boys and girls. The first three books made the New York Times Best Sellers list. Links to all of their webpages are found at http://www.danicamcke11ar.com/ math-books/ Her blog Math \& More, also found on her website, reaches out to the same audience with mathematical puzzles, links to her appearances at book signings, and broadcast promotions. Over the past seven years she may have inspired more young people to embrace mathematics than anyone else.

- JPBM announcement

DOI: http://dx.doi.org/10.1090/noti1121 